\title{
Energy Canes for Bio-Ethanol Production
}

\author{
Tanmay Kotasthane ${ }^{1^{*}}$ and Akula Umakanth ${ }^{2}$ \\ ${ }^{1}$ Assistant Nutritionist, Nimbkar Agriculture Research Institute, Phaltan 415523 \\ ${ }^{2}$ Principal Scientist, Indian Institute of Millets Research, 500030
}

Received: September 12, 2017; Accepted: October 30, 2017; Published: October 31, 2017

*Corresponding author: Tanmay Kotasthane, Assistant Nutritionist, Nimbkar Agriculture Research Institute, Phaltan 415523, E-mail:vilol.tanmay@yahoo.com

\begin{abstract}
Ethanol from lignocellulosic biomass is one of the important alternatives being considered due to the easy adaptability of this fuel to existing engines and because this is a clean energy fuel with higher octane rating than gasoline Sorghum and sugarcane feedstock is good cellulosic substrate for bio-ethanol production. Bio ethanol is considered as an important renewable fuel to partly replace fossil-derived fuels. Lignocellulosic biomass is considered as the only sustainable resource for renewable fuel; but the lingocellulosic ethanol commercialization is largely limited due to the lack of easily digestible substrate or cost effective processing technologies and cost of enzymes. Cellulosic ethanol is a bio fuel produced from wood, grasses, or the non-edible parts of plants. It is a type of bio fuel produced from lignocelluloses, a structural material which makes most of the biomass of plant. Oil demand is increasing globally; energy shortage will be a major problem in the future.
\end{abstract}

\section{Introduction}

Renewable energy sources are very important for developed and developing nations due to carbon emissions, green house effect and rise in fossil fuel prices. Developed and developing countries have policies to fulfil their energy needs in the scenario of reduction in oil supply. Currently $5-10 \%$ of ethanol is blended with petrol in several developing countries. In India, the national bio fuel policy of 2009 aims at promoting bio fuels and energy security in eco-friendly manner. India has target to rise blending of ethanol from 5\% to $20 \%$ of ethanol with petrol by 2017 . The traditional route of ethanol production through sugarcane molasses would not be meeting this huge demand because of the difficulties in increasing the sugarcane area in the country. Therefore, renewable sources of energy in the form of other bio fuel crops would be promising options in view of the emerging trends in international energy markets as well as indigenous strengths.

A farmer in developing countries has excellent opportunity to raise income through biomass sources. Bio-fuels from field crops fulfil energy and food needs and have good impact on social, ecology and environment. Biomass is the oldest source of energy and currently accounts about $10 \%$ of total primary energy consumption.

Depletion of fossil fuel requires alternative strategy or agenda. Ethanol demand increased up to six times in the current century. As per the Renewable Fuels Association, in 2010 bio-refineries global production of ethanol rise from 13 billion gallons to 19 billion

Rise in ethanol production is due to use of Corn and sugarcane is primary source for bio-ethanol [1]. IEA (2010) gives definition of first and second generation ethanol. The first generation ethanol from wheat straw and corn. First generation bio energy, like ethanol is used in many nations. Second generation bio fuels are those bio fuels produced from cellulose, hemicelluloses or lignin. Examples of 2 nd generation bio-ethanol are cellulosic. Any sort of wood, crop residues or forestry waste like sawdust and chips can be used for second generation bio fuels.

Chen, et al. [2] and Rehman, et al. [5] reported biomass sources for bio-fuel which includes paper and agriculture waste, field crops etc.

As the first generation bio fuel feed-stocks have created some concern regarding the food security and environmental issues there is a greater need in search of suitable feed-stocks for the second generation bio fuels. Though there are many feed stocks available like sugarcane, corn, miscanthus its use depends on environmental and market conditions.

\section{Materials and methods}

Normal Sorghum varieties, brown midrib sorghum varieties and high biomass sugarcane varieties were studied for cellulose and hemicelluloses content.

\section{Lignin}

Lignin is an organic material constitutes lignified elements of plants and wood .It is the second most abundant renewable carbon source on earth. About 40 to 50 million ton of lignin produced per annum worldwide. 


\section{Determination of acid detergent lignin (ADL)}

\section{Reagents}

H2SO $42 \%$ by weight

Preparation: $583 \mathrm{ml}$ pure $\mathrm{H} 2 \mathrm{SO} 4$ added in $417 \mathrm{ml}$ distilled water in a volumetric flask slowly with occasional swirling.

1. Crucible placed in petri dish containing ADF with $72 \% \mathrm{H} 2 \mathrm{SO} 4$ (150C) and stirred with glass rod to smoothen the paste and break the lumps. Let glass rod remain in the crucible; refill with $72 \% \mathrm{H} 2 \mathrm{SO} 4$ and stir at hourly intervals as acid drains away. Crucible does not need to be kept full at all times. Three additions would be sufficient. Keep crucible at 200-230C.

2. After three hours, acid filtered off. Content was washed with hot water until it is free from acid. Rinse and glass rod removed.

3. Crucible dried at $1000 \mathrm{C}$ for $8 \mathrm{~h}$ or overnight and weighed.

4. Crucible was kept in muffle furnace at 500-5000C for $3 \mathrm{~h}$.Cool it and weigh. ADL (\%) = [wt of crucible before ignition - wt of crucible after ignition]/wt of sample x 100

\section{ADF (acid detergent fibre)}

The least digestible portion of forage is fibrous component. This highly non digestible part of forage is lignin, silica, cellulose and insoluble nitrogen but not hemicelluloses. Higher ADF of forage shows lower digestibility energy levels.ADF is residue after boiling fodder sample in acid detergent solution.ADF is used to calculate digestibility total digestible nutrients (TDN).

\section{Estimation of acid detergent fibre (ADF)}

The acid detergent fibre procedure provides a rapid method for lignocelluloses determination in feedstuffs. The residue includes silica also. The difference between cell wall and acid detergent fibre is an estimate of hemi cellulose; however, this difference does include some protein attached to cell walls. The acid detergent fibre is used as a preparatory step for lignin determination.

\section{Reagents:}

1. Acid detergent solution

a. Composition: Reagent grade H2So4 standardized to $1 \mathrm{~N}$ (100\% assay) $-49.04 \mathrm{~g} / \mathrm{l}$ Cetyl trimethyl ammonium bromide (CTAB)-20.00 g

b. Preparation: Add $20 \mathrm{~g}$ of CTAB to $1 \mathrm{~N} \mathrm{H} 2 \mathrm{SO} 4$ and make the volume to one litre.

2. Decahydronaphthalein (Dekalin, reagent grade), 3 Acetone, 4 n-hexane

\section{Procedure:}

1. $1 \mathrm{~g}$ air dried sample weighed (ground to pass through 20-30 mesh screens) in a beaker of the refluxing apparatus.

2. $100 \mathrm{ml}$ acid added to detergent solution and $2 \mathrm{ml}$ decahydronephthalene.

3. Heat to boiling for 5 to 10 minutes. Reduce heat as boiling begins, in order to avoid foaming. Reflux for 60 minutes, timed from onset of boiling.

4. Filter through a weighed glass crucible on filter manifold. Rinse the sample into the crucible with minimum of hot water (9001000).Filter the liquid and repeat washing procedure.

5. Washed twice with acetone in the same manner. All lumps broke so that the solvent may come in contact with all particles of fibre.

6. Samples dried at $1000 \mathrm{C}$ for $8 \mathrm{~h}$ or overnight in hot air oven and weigh. Acid detergent fibre $(\%)=[(w t$ of crucible + fibre $)-w t$ of crucible/wt of sample] x100

\section{NDF (Neutral Detergent Fiber):}

Neutral detergent fiber is the most common measure used in feed analysis, but it is not unique class of compounds. This process involves neutral detergent that dissolves pectins, sugar and lipids leaving cellulose, lignin and hemicelluloses (Table 1).

\begin{tabular}{|c|c|c|c|c|c|c|}
\hline \multicolumn{1}{|l|}{ Table 1: Cell wall constituents of brown midrib genotypes } \\
\hline S.no & Pedigree & NDF & ADF & ADL & Cellulose & Hemi cellulose \\
\hline 1 & SSV 1 & $74.51 \pm 0.08$ & $49.00 \pm 0.23$ & $5.93 \pm 0.65$ & $43.07 \pm 0.88$ & $25.51 \pm 0.15$ \\
\hline 2 & SSV 2 & $71.59 \pm 1.00$ & $46.66 \pm 1.27$ & $4.84 \pm 0.10$ & $41.82 \pm 1.37$ & $24.93 \pm 0.27$ \\
\hline 3 & SSV 3 & $70.34 \pm 0.14$ & $45.04 \pm 0.86$ & $5.27 \pm 0.08$ & $39.77 \pm 0.78$ & $25.31 \pm 1.00$ \\
\hline 4 & SSV 4 & $68.35 \pm 1.80$ & $46.10 \pm 0.63$ & $5.72 \pm 0.06$ & $40.38 \pm 0.57$ & $22.25 \pm 1.17$ \\
\hline 5 & SSV 5 & $73.00 \pm 0.29$ & $45.37 \pm 0.37$ & $5.94 \pm 0.12$ & $39.42 \pm 0.25$ & $27.64 \pm 0.66$ \\
\hline 6 & SSV 6 & $67.91 \pm 0.70$ & $45.36 \pm 0.33$ & $5.97 \pm 0.36$ & $39.39 \pm 0.04$ & $22.56 \pm 1.03$ \\
\hline 7 & SSV 7 & $70.03 \pm 1.18$ & $47.02 \pm 0.88$ & $5.36 \pm 0.50$ & $41.66 \pm 1.38$ & $23.01 \pm 0.30$ \\
\hline 8 & SSV 8 & $76.85 \pm 1.12$ & $52.42 \pm 0.18$ & $6.09 \pm 0.32$ & $46.34 \pm 0.50$ & $24.43 \pm 1.30$ \\
\hline 9 & SSV 9 & $69.39 \pm 0.04$ & $45.43 \pm 0.79$ & $5.95 \pm 0.52$ & $39.48 \pm 0.27$ & $23.97 \pm 0.83$ \\
\hline 10 & SSV 10 & $70.48 \pm 0.06$ & $46.37 \pm 1.19$ & $6.95 \pm 0.61$ & $39.42 \pm 1.80$ & $24.11 \pm 1.13$ \\
\hline 11 & SSV 11 & $66.62 \pm 0.55$ & $42.55 \pm 0.35$ & $5.34 \pm 0.14$ & $37.21 \pm 0.21$ & $24.07 \pm 0.20$ \\
\hline 12 & Check 1 & $67.71 \pm 0.78$ & $42.52 \pm 0.12$ & $6.91 \pm 0.03$ & $35.62 \pm 0.15$ & $25.19 \pm 0.66$ \\
\hline 13 & Check 2 & $75.71 \pm 0.15$ & $51.69 \pm 0.21$ & $7.77 \pm 0.14$ & $43.93 \pm 0.06$ & $24.02 \pm 0.06$ \\
\hline
\end{tabular}




\section{Discussion}

Brown midrib sorghum genotypes compared for cellulose, hemi cellulose and lignin content. Lignin content in brown midrib derivatives were less SSV 1 (5.93\%) and SSV 2 (4.84\%) compared to check variety $1(6.91 \%)$ and Check variety $2(7.77 \%)$. The hydrolysis of lignocellulosic material into fermentable sugars is a crucial stage, which mainly determines the overall process. Ethanol production from lignocellulosic biomass seems very attractive and sustainable due to several reasons, among which the renewable and ubiquitous nature of biomass and its non competitiveness with food crops are the major ones.

Cell wall constituents of High biomass sorghum lines

\begin{tabular}{|c|c|c|c|c|}
\hline Entry & NDF & ADF & ADL & Cellulose \\
\hline SSB 1 & $70.01 \pm 20$ & $43.2 \pm 16$ & $7.21 \pm 12$ & $44.32 \pm 10$ \\
\hline SSB 2 & $69.20 \pm 12$ & $42.3 \pm 10$ & $6.94 \pm 9$ & $39.20 \pm 13$ \\
\hline SSB 3 & $72.03 \pm 13$ & $41.2 \pm 11$ & $6.45 \pm 10$ & $41.10 \pm 12$ \\
\hline SSB 4 & $68.30 \pm 15$ & $43.2 \pm 13$ & $7.01 \pm 12$ & $42.15 \pm 10$ \\
\hline Check & $75.71 \pm 0.15$ & $51.69 \pm 0.21$ & $7.77 \pm 0.14$ & $43.93 \pm 0.06$ \\
\hline
\end{tabular}

Lignin content in high biomass line were lowest in SSB $3(6.45 \%)$ followed by SSB 2 (6.94\%).Biomass represents a renewable, versatile and abundant resource in nature that has multifunctional utilities and hemicelluloses, has found its role in the production of various value-added chemicals. (figure1) Cellulose consists of long chains of glucose monomers gathered into micro fibril bundles. Cellulosic biomass is receiving growing attention as a renewable feed stock, Lignocellulosic biomass is mainly composed of plant cell walls, with the structural carbohydrates cellulose and hemi cellulose and heterogeneous phenolic polymer lignin as its primary components. The cell walls contain about $40 \%$ cellulose, $30 \%$ hemi cellulose and $15 \%$ lignin on a dry weight basis. In recent years, introduction of sorghum plants containing the BMR gene generated much interest because plants with this trait have lower lignin concentrations than conventional types (figure 2).

At present, researchers are more interested in sugars-based ethanol (first generation ethanol) which can also be used as food source (examples are corn, sorghum and sugarcane) to non food based ethanol (second generation ethanol) such as lignocellulosic biomass and as a consequence limit the competition between fuels and food production. Field crops are one of the best sources of renewable energy which can be used as feed-stock for bio fuels production (figure 3).

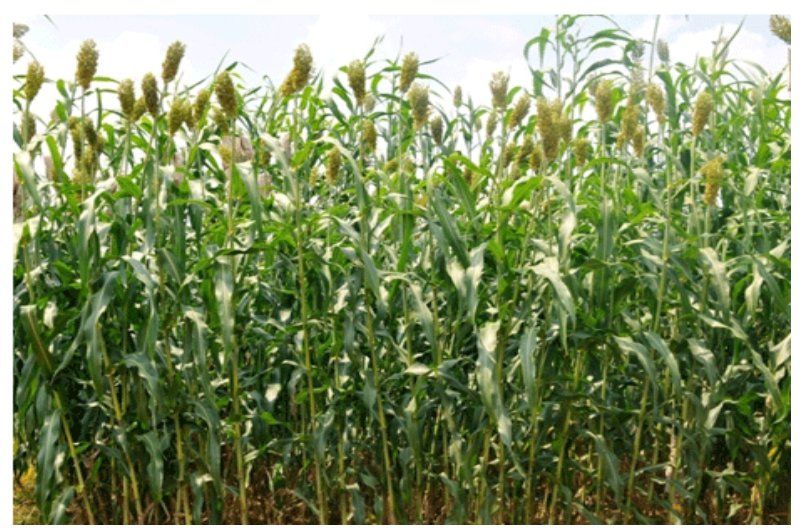

Figure 1: Sorghum field view

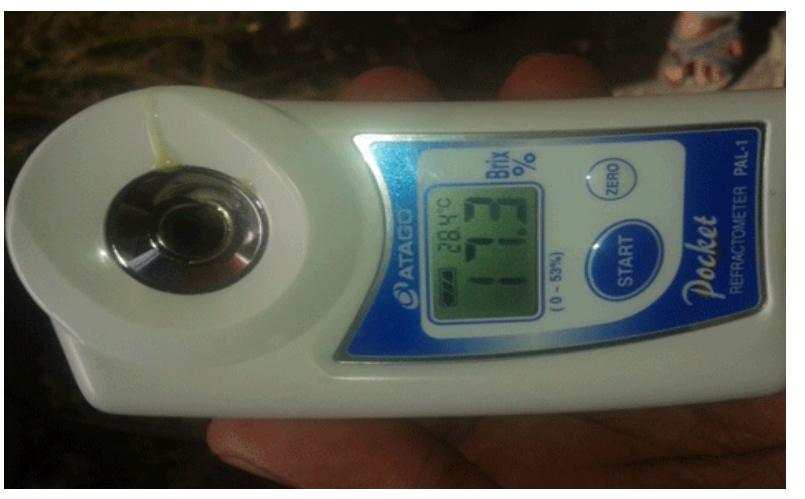

Figure 2: Atago Pal Brix refractometer

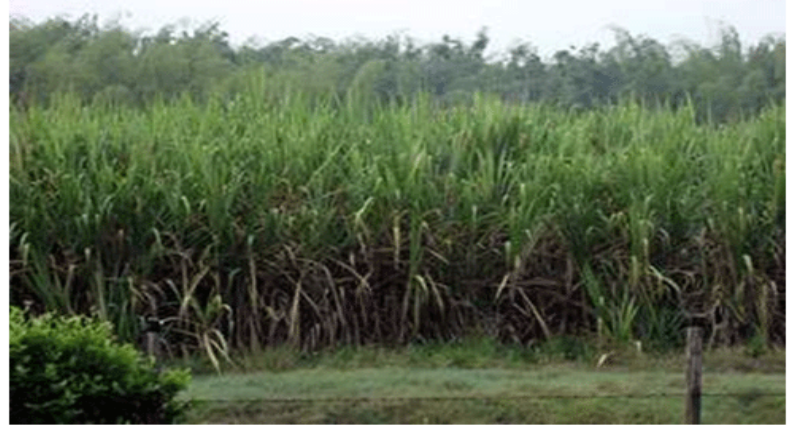

Figure 3: Sugarcane

(Pinnamaneni Srinivasa, et al. [3]).observed significant differences in BMR mutants for stover yield plant height, stover yield nitrogen content, in vitro organic matter digestibility (IVOMD) and acid detergent lignin content ADL Brown midrib (BMR) mutant plants evidence the importance of genetic selection to improve the digestibility of forages. In studies with mutant plants, it was observed that, despite their lower agronomic value, the genotype had lower content of lignin and cellulose and higher digestibility, intake and productivity per animal (Oliver, et al. [4]). (Poliana Batista de Aguilar, et al. 2014) observed that for neutral detergent fibre (NDF) and acid detergent fibers (ADF) there were 
no differences between genotypes, the mean values were 58.08 and $35.28 \%$, respectively. Sorghum cultivars with reduced lignin can pave a better path to increase cellulosic ethanol pro $\neg$ duction as compared with other crop residues and also improve process economics targeting higher conver $\neg$ sion efficiency. Reduced lignin content will be highly beneficial for improving biomass conversion yields through biomass pre-treatment with dilute acid and also for the production of 5-HMF, ethylene glycol, LA, beside pentose and hexoses.

\section{Conclusion}

The sorghum brown midrib mutants have reduced lignin content in the cell walls and vascular tissues, which could potentially be advantageous for cellulosic bio fuel production. Meanwhile, both dry matter yield and plant height were decreased in the BMR mutant. BMR mutant plants (brown midrib trait) are phenol typically characterized by the presence of brownish pigments on the midrib of the leaf and in the stem. These pigments are strongly associated with the lignin as they persist in the cell wall after the removal of hemi cellulose and cellulose. A brown midrib sorghum has high digestibility than other sorghum genotypes. There is a more digestible NDF fraction in both SSV1 and SSV8 forage sorghums, corresponding to a greater DM. Lower ADL found in SSV 2. ADL content in high biomass line were lowest in SSB 3 (6.45\%) followed by SSB 2 (6.94\%).The fresh biomass ranged from 30-92 tons/ha and dry biomass ranged from 16 to 40 tons/ha. Sorghum cultivars with reduced lignin and high biomass sugarcane can pave a better way to increase second generation cellulosic ethanol production as compared with other crop residues and also improve process economics targeting higher conversion efficiency. Reduced lignin content will be highly beneficial for improving biomass conversion yield. Identification of diversifying plant species that may use as bioenergy crop is important. Ethanol yield is important trait which depends on bioconversion cellulosic biomass.

\section{References}

1. Berg C. World fuel ethanol analysis and outlook. Japan. 2004.

2. Chen W-H, Ye SC, Sheen HK. Hydrolysis characteristics of sugarcane bagasse pretreated by dilute acid solution in a microwave irradiation environment. Applied Energy. 2012;93:237-244.

3. Rao PS, Deshpande S, Blummel M, Reddy BVS, Hash T. Characterization of brown midrib mutants of sorghum(Sorghum bicolour (L) Moench). European Journal of Plant Science and Biotechnology. 2012;6(1):7175.

4. Oliver AL, Grant RJ, Pederson JF, O’Rear J. Comparison of BrownMidrib-6 and -18 forage sorghum with conventional sorghum and corn silage in diets of lactating dairy cows. Journal of Dairy Science. 2004;87(3):637644 .

5. Rehman MSU, Kim I, Chisti Y, Han JI. Use of ultrasound in the production of bio-ethanol from lignocellulosic biomass. Energy Education Science and Technology Part A: Energy Science and Research. 2013;30(2):1391-1410. 